Revista Bioética

Print version ISSN 1983-8042 On-line version ISSN 1983-8034

Rev. Bioét. vol.28 no.4 Brasília Out./Dez. 2020

Doi: 10.1590/1983-80422020284430

\title{
PESQUISA
}

\section{Perfil e vozes dos participantes de pesquisas clínicas no Brasil}

Karla Patrícia Cardoso Amorim ${ }^{1}$, Volnei Garrafa ${ }^{2}$, Alana Dantas de Melo ${ }^{1}$, Andressa Vellasco Brito Costa ${ }^{1}$, Gabriella Caldas Leonardo Oliveira ${ }^{1}$, Heitor Giovanni Lopes ${ }^{1}$, Eduardo Judene da Silva Pereira ${ }^{1}$, Francisco Ademar Fernandes Júnior ${ }^{1}$

1. Universidade Federal do Rio Grande do Norte, Natal/RN, Brasil. 2. Universidade de Brasília, Brasília/DF, Brasil.

\section{Resumo}

Este estudo de caso buscou traçar o perfil socioeconômico de participantes de ensaios clínicos em centro de pesquisa brasileiro, analisando suas decisões, motivações e experiências, seu conhecimento sobre riscos, benefícios e cuidados dispensados e o processo de consentimento. Dados de 327 participantes foram coletados, realizando-se entrevistas semiestruturadas com 19 deles. Nas pesquisas executadas no centro estudado houve maior participação de homens, de pessoas com poucos anos de estudo formal e de baixa renda. A maioria é aposentada, não tem assistência privada à saúde e tende a não perceber os efeitos da investigação ou superestimar os benefícios médicos diretos. A busca pelo tratamento médico foi o principal fator que influenciou suas decisões/participação, e a assinatura do termo de consentimento livre e esclarecido não garantiu a expressão da autonomia. Conclui-se que o perfil e o conteúdo dos discursos dos participantes são sensíveis indicadores de vulnerabilidade e desigualdade social.

Palavras-chave: Relações pesquisador-sujeito. Ensaios clínicos como assunto. Vulnerabilidade social. Equidade em saúde. Fatores socioeconômicos. Ética em pesquisa. Bioética.

\section{Resumen \\ Perfil y voces de los participantes de investigaciones clínicas en Brasil}

Este estudio de caso trató de esbozar el perfil socioeconómico de participantes de ensayos clínicos en un centro de investigación brasileño, analizando sus decisiones, motivaciones y experiencias, su conocimiento sobre los riesgos, beneficios y cuidados prestados y el proceso de consentimiento. Se recopilaron datos de 327 participantes y se realizaron entrevistas semiestructuradas con 19 de ellos. En las investigaciones realizadas en el centro estudiado hubo una mayor participación de hombres, de personas con pocos años de educación formal y con bajos ingresos. La mayoría es jubilada y no tiene asistencia sanitaria privada, tiende a no percibir los efectos de la investigación o a sobrestimar los beneficios médicos directos. La búsqueda de tratamiento médico fue el factor principal que influyó en sus decisiones/participación, y la firma del término de consentimiento libre e informado no garantizó la expresión de la autonomía. Se concluye que el perfil y el contenido de los discursos de los participantes son sensibles indicadores de vulnerabilidad y desigualdad social.

Palabras clave: Relaciones investigador-sujeto. Ensayos clínicos como asunto. Vulnerabilidad social. Equidad en salud. Factores socioeconómicos. Ética en investigación. Bioética.

\begin{abstract}
Profiles and voices of participants in clinical research in Brazil

This case study aimed to trace the socioeconomic profile of participants in clinical research at a Brazilian research center, analyzing their decisions, motivations, experiences, knowledge of risks, benefits and health care provided, and the consent process. The data of 327 participants were collected, and semi-structured interviews conducted with 19 of them. In the research carried out at the center studied there was a greater participation of men and of people with few years of formal education and low income. Most are retired and have no private health plan, tend not to notice the effects of the investigation, or to overestimate its direct medical benefits. The search for medical treatment was the main factor influencing their decisions/participation, and signing the informed consent form did not guarantee the expression of autonomy. We concluded that the participants' profile and speeches content are sensitive indicators of vulnerability and social inequality.

Keywords: Researcher-subject relations. Clinical trials as topic. Social vulnerability. Health equity. Socioeconomic factors. Ethics, research. Bioethics.
\end{abstract}

Aprovação CEP-Conep CAEE 01109412.9.0000.5292

Declaram não haver conflito de interesse. 
Em decorrência da aproximação entre universidade e indústria, a atividade científica na área da saúde - especialmente os ensaios clínicos ${ }^{1}$ - deixou de ser prática amadora, tornando-se, no século XX, um complexo científico-industrial-tecnológico ${ }^{2}$. Os diversos documentos nacionais e internacionais que regulamentam a matéria não são totalmente capazes de garantir o respeito à integridade dos participantes de pesquisas, evidenciando-se ainda hoje conflitos e abusos.

Destacam-se como exemplo estudos desenvolvidos em países periféricos sobre a transmissão vertical do HIV em mulheres grávidas por meio de grupos placebo-controlados ${ }^{3}$. Esses casos levam a concluir que, em contextos de grande desigualdade social, pessoas sem acesso a cuidados básicos de saúde tornam-se mais vulneráveis e propensas a situações iníquas e de sofrimento. É imperativo refletir a respeito da dignidade do ser humano e de sua autonomia, passando pelo termo de consentimento livre e esclarecido (TCLE), cuja mera assinatura, sem a devida compreensão, levanta questões complexas em contextos de vulnerabilidade socioeconômica e analfabetismo.

O motivo pelo qual os sujeitos aceitam participar de pesquisas clínicas é outra demanda necessária e urgente ao debate sobre saúde pública e ética em pesquisa. Trabalhos assim são escassos ${ }^{4-6}$, exigindo reflexão e atualização das pautas relativas às pesquisas com seres humanos. Pouco se sabe dos participantes de pesquisa, pouca atenção é dispensada a eles, pouco se fala deles. Nesse sentido, este estudo envolveu participantes de ensaios clínicos da área de cardiologia realizados em um centro de pesquisa do Nordeste brasileiro. Com o intuito de conhecer quem são essas pessoas, seu perfil socioeconômico foi traçado e foram analisadas questões relacionadas às suas motivações, decisões e experiências em estudos clínicos, ao seu conhecimento dos riscos e benefícios envolvidos, aos cuidados dispensados durante e após o estudo e ao processo de consentimento livre e esclarecido.

\section{Método}

Este estudo foi realizado em centro de pesquisa clínica privado, conveniado ao Sistema Único de Saúde (SUS), localizado na cidade de Natal/RN. Analisaram-se documentos de 327 pacientes que participaram ou estavam participando de ensaios clínicos na área de cardiologia no centro de pesquisa, dos quais 19 também foram entrevistados.

Trata-se de pesquisa observacional, do tipo estudo de caso, de caráter exploratório e descritivo, com abordagem qualiquantitativa em duas etapas. A primeira, quantitativa, visou estabelecer o perfil socioeconômico (idade, sexo, grau de escolaridade, renda familiar, lugar de residência, acesso a assistência privada à saúde etc.) dos 528 participantes dos 26 ensaios clínicos desenvolvidos no centro estudado. $O$ intuito dessa etapa era realizar um censo, mas dados de 201 pessoas não foram disponibilizados, levando a uma amostra total de 327 pacientes. Esses dados foram coletados dos prontuários e protocolos de pesquisa datados de outubro de 2012 a julho de 2013. Frequências absolutas, percentuais e distribuições desses dados foram registrados e analisados no programa SPSS para Windows.

Na segunda etapa, qualitativa, realizaram-se entrevistas semiestruturadas com 19 participantes, identificados pela letra " $S$ " seguida de um número e selecionados por conveniência - ou seja, entrevistaram-se sujeitos que puderam ser convidados no centro de pesquisa. A quantidade de entrevistados foi determinada por saturação, isto é, a amostragem não obedeceu a critérios numéricos, mas foi concluída quando a repetição de sentidos dos discursos tornou improvável aprofundar a compreensão do tema ${ }^{7}$.

Os critérios de inclusão na segunda fase foram: ter participado ou estar participando de ensaio clínico; ser maior de 18 anos; e não apresentar qualquer alteração, distúrbio, incapacidade ou doença mental que prejudicasse ou impedisse o entendimento no momento da entrevista. Buscou-se captar nos depoimentos informações a respeito da motivação, decisão e experiência de participar de estudos clínicos, assim como sobre o processo de consentimento, o conhecimento acerca dos riscos e benefícios e os cuidados dispensados aos sujeitos durante e após o estudo.

As entrevistas seguiram roteiro semiestruturado, sendo gravadas e transcritas na íntegra. Utilizou-se método de análise de conteúdo de acordo com os passos descritos por Bardin ${ }^{8}$, e o software NVivo foi empregado como ferramenta auxiliar com o intuito de organizar o material e estabelecer objetivamente a frequência do que foi verbalizado.

Os dados qualitativos foram tratados em três etapas. A primeira, de pré-análise, consistiu na organização do material, iniciando-se com leitura flutuante e repetida das transcrições, buscando um sentido geral, e posterior identificação de pontos convergentes representativos e significativos. Na segunda etapa o material empírico foi explorado, codificado e decomposto, sendo definidas sete categorias de análise, cujas unidades de significação foram agrupadas, classificadas, categorizadas e investigadas. 
Na terceira e última etapa, os resultados e as interpretações converteram o conteúdo recolhido em dados qualitativos e análises reflexivas. Assim, realizaram-se sínteses, inferências e articulações entre as informações obtidas e o aporte teórico da pesquisa.

\section{Resultados}

Para favorecer a apresentação e compreensão dos resultados, os dados quantitativos (relacionados às informações documentais dos 327 participantes do centro de pesquisa) e qualitativos (baseados nas entrevistas) serão expostos conjuntamente, quando possível, e, de forma complementar, por categorias de análise do estudo.

A análise dos 327 documentos incluídos na primeira etapa desta pesquisa indicou que $80,4 \%$ dos pacientes participaram de ensaios clínicos em fase III, $14,1 \%$ em fase II e 5,5\% em fase IV. Nos ensaios já finalizados, apenas dez pacientes não participaram até a conclusão: cinco morreram, dois tiveram quadro de saúde agravado, dois deixaram o estudo sem registro de motivação e um pediu para sair.

\section{Quem eram os participantes dos ensaios clínicos?}

Com base nos registros dos 327 pacientes, $66,7 \%$ eram homens e $33,3 \%$ mulheres, com idades distribuídas conforme o Gráfico 1. Apenas 107 $(32,7 \%)$ documentos indicavam o grau de escolaridade do paciente, dos quais $55(51,4 \%)$ tinham apenas o ensino fundamental, $25(23,4 \%)$ eram analfabetos, $19(17,8 \%)$ haviam cursado o ensino médio e apenas $8(7,5 \%)$ haviam completado o ensino superior. Sobre a profissão do paciente, verificou-se que grande parte $(33,6 \%)$ era aposentada, e $23,5 \%$ dos registros não indicavam essa informação. Apenas um prontuário informava a renda familiar do paciente, que recebia até 1 salário mínimo. Entre os 19 entrevistados, 8 apresentavam essa mesma renda, 9 recebiam até 2 salários mínimos, um recebia 3 e um recebia 4 salários mínimos.

Gráfico 1. Distribuição etária dos participantes de ensaios clínicos no centro de pesquisa

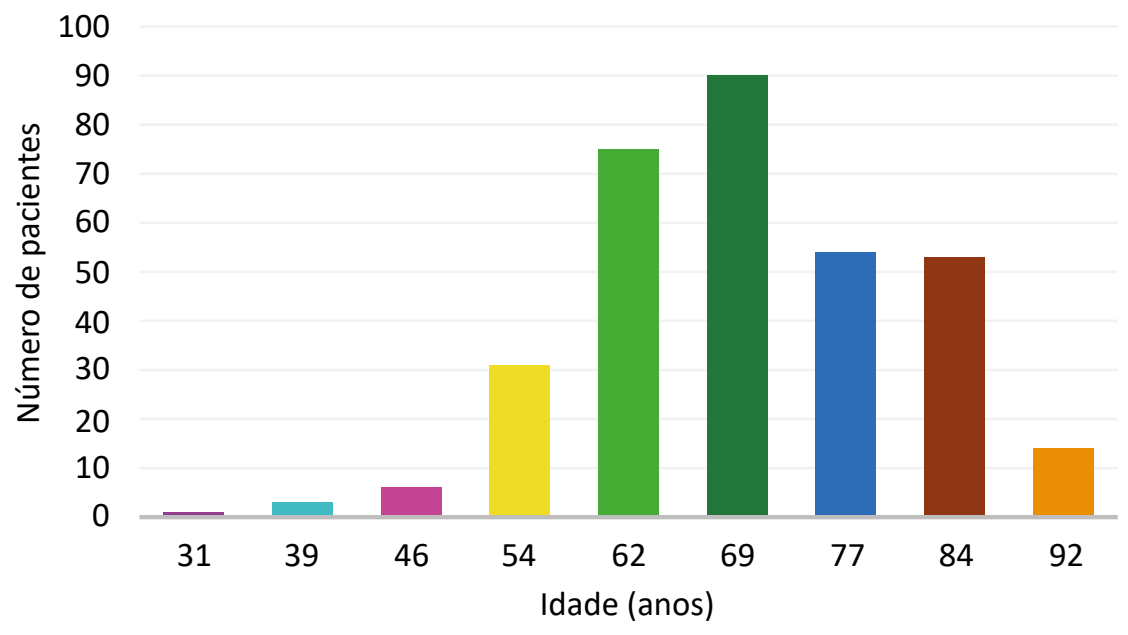

O local de residência dos participantes não constava em $5,5 \%$ dos formulários, mas os demais demonstraram que 49,2\% moravam em Natal e $45,3 \%$ residiam em outros municípios do estado. Dos que moravam na capital, a maioria residia na Zona Oeste $(15,9 \%$ do total investigado e $32,3 \%$ analisando-se só os dados de Natal), região mais pobre da cidade. Observou-se ainda que a maioria dos pacientes $(79,5 \%)$ não tinha plano de saúde privado, incluídos nesta situação os 19 entrevistados, e 3,4\% dos documentos não indicava este dado.

\section{Como ficaram sabendo da pesquisa e por que decidiram participar?}

A maioria dos entrevistados relatou que soube da pesquisa após ter infartado ou apresentado quadro cardíaco grave. Quinze vieram encaminhados de hospitais públicos e foram convidados a participar da 
pesquisa por um médico ou enfermeiro após realizar algum procedimento na instituição onde fica situado o centro de pesquisa.

Em síntese, decidiram aceitar o convite por terem sofrido quadro grave, ameaçador da vida, e desejarem se curar e ser bem cuidados. Naquele momento, julgaram ser a melhor opção, dada a garantia de exames e acompanhamento médico regular e frequente, algo deficitário no serviço público. As falas a seguir são emblemáticas:

"[Decidi participar] porque eu achei que era melhor, eu ia ser mais atendida com mais frequência" (S1).

"Primeiramente, porque eu não tenho plano de saúde e não tinha condições (...) porque eu tenho que ser avaliada de três em três meses, tenho que fazer exames, porque eu sou diabética, entendeu? Sou hipertensa, eu tenho que ter um controle, entendeu?" (S3).

"A razão é do meu bem-estar, da minha saúde. Já tive esse problema de infarto, já botei o marca-passo, então é uma coisa que eu tenho que ter, eu não tenho plano de saúde. Esses postos de saúde, ninguém pode contar com eles, né?" (S6).

Alguns pacientes consideravam a pesquisa como plano de saúde ou tratamento, conforme se observa nestas falas:

"Perguntaram se eu gostaria de entrar nessa pesquisa, nesse tratamento. Eu fiquei assim, não sabia direito, a gente do interior não sabe de nada, né? Aí depois a enfermeira disse: 'é muito bom pra sua saúde; aceite, viu, que seu problema é sério'. E depois eu aceitei" (S17).

"Eu tive um enfarte, né? Há uns dois anos atrás. Aío médico que fez a operação, quando eu saí, me chamou lá no consultório dele e perguntou se eu gostaria de fazer parte de um plano, porque era muito importante pra mim" (S12).

"Eu vinha sendo acompanhada por doutora $Y$, fazendo muito sacrifício pra pagar as consulta particular. Aí um dia ela me chamou e me falou sobre essa pesquisa: 'eu vou lhe incluir nesse plano, porque eu vejo que a senhora é uma pessoa que se esforça muito pra pagar essa consulta, e o acompanhamento da pesquisa é uma coisa muito boa pra senhora'"'(S4).

\section{Como se deu o processo de consentimento?}

Todos os entrevistados confirmaram ter assinado o TCLE, mas a maioria confessou ter pedido ajuda para entendê-lo, enquanto outros declararam ter tido dificuldades, e poucos revelaram, ainda, que não o leram. Embora quatro pacientes tenham relatado facilidade para entender o TCLE, nenhum deles soube responder quando algumas questões - acerca, por exemplo, dos riscos presentes no estudo - foram aprofundadas na entrevista. Os participantes desconheciam os procedimentos metodológicos e seus efeitos adversos, e associavam os objetivos da pesquisa ao seu tratamento cardiológico, acreditando que o protocolo fora baseado em suas necessidades e interesses. As falas a seguir ilustram o processo de consentimento:

"Porque (...) eu podia ter lido ou não ler? Não li. Ela disse assim: 'a senhora tem que assinar esses termos tudinho assim, e assim'; eu assinei, mas não li" (S1).

"Não. Foi um pouco difícil, eu fiquei em dúvida em alguma coisa, certo? Porque são palavras mais, que não chega à minha altura, e eu fiquei meio... mas tudo bem" (S12).

"Na verdade, eu não li completo, não. Mais ou menos. A menina que fez esse plano da medicação me explicou mais ou menos, assim por alto, e eu assinei os termos sem ler completamente, direto" (S14).

Verifica-se ainda que os participantes dos ensaios clínicos não compreendem o que significa "placebo", visto que apenas 2 dos 19 pacientes entrevistados abordaram essa questão, e somente 1 deles utilizou tal termo. $O$ relato a seguir expõe esta séria questão ética, pois demostra que S12, apesar de estar há quase dois anos na pesquisa, só veio a conhecer o tema em sua última consulta:

"Na última vez que eu tive aqui, a menina fez um levantamento comigo e disse: 'essa medicação que a gente tá passando, a gente não sabe, vem lá dos Estados Unidos e a gente passa para o cliente, apesar de tudo. Ela pode ser boa pra você, pode servir pra alguma coisa e pode não servir de nada, ser uma água no pote'. Foi isso que ela me falou. Eu falei 'tudo bem', aí ela disse: 'você quer continuar ou não?'”' (S12).

A fala a seguir revela com bastante clareza como a ocasião do recrutamento demanda atenção e reflexão em prol de um respeitoso e verdadeiro processo de consentimento:

"Saí da UTI, fui pra enfermaria, aí na saída, já estava de alta e tinha que deixar o leito pra chegar outro paciente, eu assinei pra ficar nesse estudo. Ela disse que era pro bem, porque 
precisava, porque tinha tido um infarte, precisava tomar essa medicação, não custava nada. Eu tava muito agitada! Aquele nervoso" (S10).

Os participantes tinham conhecimento dos riscos $e$ benefícios a que estavam expostos?

Nenhum entrevistado falou com convicção a respeito dos riscos. Onze disseram que não os conheciam, e oito afirmaram saber, porém não se lembravam quais eram:

"Os riscos? Como assim? Não" (S2).

"Mais ou menos. Não tô entendendo direito. Eu tenho o papel em casa completinho, li por cima, assim, mais ou menos. Se não for ruim pra mim, é bom" (S14).

"Nem lembro. Eu tava tão ruim nesse dia" (S17).

Este último relato reforça o cuidado necessário no momento de recrutar pessoas para participar de pesquisas na área da saúde, resguardando sua dignidade e autonomia. Os entrevistados associaram os benefícios ao tratamento de qualidade que vinham recebendo.

Quais são os cuidados dispensados aos sujeitos de pesquisa durante e após o estudo?

Nenhum entrevistado soube falar sobre os cuidados pós-estudo. Quinze participantes afirmaram que nada foi dito a respeito, e os outros quatro não se lembravam do que se tratava. Muitos demonstraram também grande preocupação na hora da entrevista, manifestando tristeza e insegurança a respeito da continuidade do seu tratamento quando terminasse o estudo. Tais aspectos são confirmados nas seguintes falas:

"Não, não me lembro se foi prometido, mas eu acho que não. Depois, não" (S1).

"Não, até aqui não. Depois da pesquisa eu não sei o que vai acontecer, porque eu não tenho dinheiro pra pagar médico cardiologista, e aqui eu achava bom porque eu tinha cardiologista sem pagar. Posto ninguém conta, né?" (S6).

"Se tá no papel que foi assinado, eu não tô entendendo, eu não entendi. Após encerrar a pesquisa eu não sei o que vai ser" (S14).

A fala a seguir em particular revela a total vulnerabilidade do participante, seu grau de necessidade e alienação e, ao mesmo tempo, denuncia o grave contexto social envolvido na discussão sobre ensaios clínicos:

“Não falou, eu não lembro. Quando terminar, sei não. Eu até disse: 'mulher, quando terminar não me tire não, qualquer coisa me bote aqui'. Eu disse qualquer coisa" (S19).

\section{Como avaliam a experiência de participar de pesquisa clínica?}

Os resultados apresentados até o momento já permitem delinear a resposta a essa questão. De forma geral, os participantes avaliaram como bom, muito bom e ótimo o fato de estarem participando da pesquisa. Falaram da boa assistência, do acesso à medicação e da garantia de acompanhamento regular. Em suma, estão satisfeitos com a assistência que receberam ou estão recebendo, como exprime o depoimento a seguir:

"É exame, é o médico, uma operação se precisar amanhã ou depois, na hora. Agora pelo SUS, né? Pelo SUS! Eu não tenho que reclamar de nada, nem de médico, nem de hospital, tudo finalmente é muito bom. Sou muito bem atendido aqui. Maravilha!" (S11).

\section{Reflexões espontâneas}

Nesta última categoria serão expostas as falas que os entrevistados proferiram espontaneamente ao fim da entrevista. Apenas três pacientes não quiseram adicionar comentários. Dos demais, quatro expressaram preocupação e tristeza com o fim da pesquisa e vontade de permanecer no centro; um tinha dúvidas a respeito dos sintomas sentidos, questionando se eram efeito do medicamento estudado ou dos outros remédios que tomava; oito comentaram o quanto gostavam dos profissionais, da assistência e dos cuidados recebidos; e nove agradeceram a excelência e a qualidade desses cuidados.

Merecem destaque, neste momento, as reflexões singulares de S12, que deixam transparecer questões que ultrapassam a visão eminentemente técnica, contemplando igualmente aspectos políticos, sociais e éticos envolvidos na pesquisa clínica:

"Por que a gente não tem acesso aos exames? Eu creio que é um direito nosso como paciente, né? É ver os exames, mesmo que eu não entenda nada, mas vendo os exames a gente se sente bem (...). Agora realmente eu fiquei balançado quando eu senti que estava sendo uma cobaia, porque na 
verdade aquele remédio pode não ser nada (...). $E$, com certeza, tem esse pessoal do interior que tem todas essas nossas dúvidas, mas a gente que é mais esclarecido, a gente entende (...). Mas isso tudo que acontece é justamente o nosso sistema que é muito precário. Se nós tivéssemos um bom plano de saúde, se o governo bancasse assim pra todo mundo ter um plano de saúde bom (...). Muitas vezes a pessoa entra num negócio desse, naquela vontade de um atendimento que não existe, não existe atendimento nenhum, e no pensamento que vai ter alguma coisa em benefício dele próprio. E a gente sabe que, na verdade, isso é uma pesquisa que vai beneficiar, tudo bem, num futuro, ninguém sabe quando. Vai beneficiar o pesquisador porque ele vai ganhar muito sobre a patente da medicação, o laboratório vai ser beneficiado porque vai vender a medicação, e a pessoa que vai receber a medicação, tudo bem, vai ser bom pra ele, porque ele vai comprar e vai ser beneficiado, mas isso era pra o governo bancar isso aí e tudo, não a gente comprar essa medicação que tá sendo pesquisada agora e muita gente sendo usada como cobaia" (S12).

\section{Discussão}

Os dados mostram que a participação em pesquisas clínicas foi vista pelos sujeitos como tratamento médico alternativo, possivelmente indicando a precariedade dos serviços de saúde disponíveis para a população - ocorrência comum em diversas comunidades ao redor do mundo ${ }^{4-6,9-13}$. Ao demonstrar que alguns pacientes consideram a pesquisa como plano de saúde ou tratamento garantido, fica evidente a incompreensão do que significa participar dela. Isso aponta a necessidade de estabelecer visão mais crítica sobre o TCLE, o processo de consentimento e o respeito à autonomia, principalmente em contextos de vulnerabilidade.

A situação torna-se mais complexa ao se associar os relatos elencados à imagem dupla do médico-pesquisador. Os discursos coletados durante as entrevistas evidenciam que os pacientes tendem a não questionar o médico ${ }^{14}$ devido à relação de confiança criada e à autoridade desse profissional ${ }^{15,16}$. É imperativo questionar esse duplo papel, assim como o desentendimento constatado em relação à pesquisa e ao tratamento ${ }^{10,17}$.

O consentimento esclarecido deveria atestar a compreensão do participante acerca da diferença entre terapia comprovada e droga experimental, e a falha em esclarecê-lo pode induzir o paciente a participar de forma inapropriada ${ }^{18}$. Nesse contexto, o termo "pesquisa terapêutica" deve ser evitado por ser potencialmente enganoso ${ }^{19} \mathrm{e}$ induzir confusão. Tal fato foi evidenciado neste estudo e descrito nos resultados, demonstrando que, além de desconhecerem aspectos fundamentais da pesquisa - como objetivo, procedimentos metodológicos e efeitos adversos das substâncias ${ }^{10,20}$-, os pacientes acreditavam estar recebendo tratamento individualizado, específico às suas necessidades de saúde.

Esses equívocos são indicadores sensíveis de falha no processo de consentimento, resultando em relação baseada em decisão não informada, alimentando esperanças fundadas em critérios incorretos e comprometendo, inclusive, a avaliação de riscos e benefícios por parte dos pacientes ${ }^{10}$. Observa-se que a maioria dos participantes dos ensaios clínicos não entende o significado de "placebo", ou seja, que há $50 \%$ de possibilidade de não receber medicação alguma ${ }^{21}$. Essa condição foi constatada neste estudo, em que apenas dois participantes abordaram o tema, e somente um utilizou o vocábulo apropriado.

O consentimento dos participantes de pesquisas clínicas deve ser encarado como processo educativo, visando respeitar sua autonomia, para além da assinatura de um papel, conforme percebido neste estudo. Baixos níveis socioeconômicos e de escolaridade estão associados a menor capacidade de questionamento e menor confiança durante a obtenção do TCLE ${ }^{10,22}$. O centro de pesquisa estudado está situado na região Nordeste do Brasil, na qual ainda se concentra o maior número de analfabetos do país $(54,2 \%)^{23}$. Tal situação é agravada ao se considerar os analfabetos funcionais, representados em maior número pelas pessoas de mais idade ${ }^{23}$ - faixa etária da maioria dos participantes pesquisados.

Pelo fato de a pesquisa clínica de novos medicamentos implicar mais riscos potenciais para os sujeitos, estes deveriam ter mais discernimento e estar mais conscientes e esclarecidos para aceitar participar; entretanto, o quesito escolaridade tem sido pouco considerado nesse debate ${ }^{10}$. A análise dos TCLE de pesquisas clínicas agrava ainda mais a preocupação com esse aspecto: trata-se de documentos usualmente longos e que por vezes apresentam termos complexos e linguagem médica e técnica que mesmo aqueles com nível educacional elevado podem ter dificuldade de compreender ${ }^{10,24}$. 
Observa-se que, na prática, o consentimento se resume à transmissão de informações e assinatura do termo, distante de decisões esclarecidas e conscientes, principalmente em casos que envolvem vulnerabilidades sociais ${ }^{10}$. Essa condição já pode ser considerada mecânica, incorporada de forma vertical e acrítica ${ }^{25}$.

A relação entre ensaios clínicos e vulnerabilidade social muitas vezes não é abordada. Neste estudo, constatou-se que os dados capazes de revelar o perfil socioeconômico dos pacientes não estavam presentes na maioria dos documentos analisados. Defende-se que evidenciar e debater o perfil socioeconômico dos participantes é de extrema importância e merece especial atenção diante da atual lógica de mercado que permeia as pesquisas clínicas, principalmente nos cenários de desigualdade social ${ }^{10}$. Conflitos de interesse e efeitos adversos da crescente relação de pesquisadores, universidades e serviços de saúde com a indústria farmacêutica têm sido evidenciados ${ }^{26}$.

Todas essas questões precisam ser explicitadas aos pacientes, sobretudo quando apresentam baixo nível educacional e desconhecimento sobre a natureza das pesquisas clínicas e sua distinção dos cuidados médicos. A vulnerabilidade econômica e social é evidente em contextos de difícil acesso a serviços básicos de saúde e medicamentos, e esse cenário é propício para a proliferação de pesquisas com padrões éticos questionáveis ${ }^{10}$.

Ao negligenciar esse aspecto, a comunidade científica de certa forma contribui para sua prática. As poucas pesquisas que buscam analisar o perfil dos sujeitos de ensaios clínicos apontam que normalmente participam pessoas mais pobres, sem acesso a cuidados de saúde ${ }^{27}$. Outro estudo, que visava analisar estratégias para aperfeiçoar o recrutamento para ensaios clínicos entre pacientes latino-americanos, observou que quase todas as pessoas com salários mais baixos e cuidados de saúde deficientes aceitaram participar ${ }^{28}$.

Conforme exposto nos resultados desta pesquisa, todos os entrevistados haviam recentemente sofrido episódio grave e ameaçador da vida. A escuta ativa dessas pessoas sinaliza que o consentimento foi por vezes dado em contexto de pressão e vulnerabilidade, em que somente teriam acesso à assistência elogiada por todos se aceitassem participar do estudo proposto. Em situações como essa, o paciente se sente compelido a participar e permanecer na pesquisa ${ }^{29}$. Os depoimentos demonstram que os entrevistados estavam extremamente vulneráveis e dependentes do médico, quadro refletido e agravado pelo desconhecimento de questões implicadas e relacionadas à sua participação no protocolo de pesquisa ${ }^{10,30}$.

Afirma-se, mais uma vez, que nesta pesquisa o TCLE mostrou-se insuficiente para expressar decisão verdadeiramente autônoma. Outros estu$\operatorname{dos}^{10,31-33}$ evidenciam a mesma conclusão, embora os achados de Lacativa e colaboradores ${ }^{34}$ sejam discrepantes. Imperativo ético básico é esclarecer riscos e benefícios a que os participantes são ou serão expostos em pesquisa clínica, mas voluntários frequentemente consentem em participar com pouco ${ }^{35,36}$ ou nenhum conhecimento sobre informações importantes ${ }^{10}$. As falas dos entrevistados nesta pesquisa revelam que nenhum deles soube discorrer sobre os riscos.

A garantia de cuidados pós-estudo também parece não ter sido abordada com clareza, suscitando a hipótese de não ser tratada rotineiramente nos estudos do centro pesquisado, constituindo grave questão ética ${ }^{10}$. Diante do observado, vê-se a real necessidade de efetiva assistência à saúde e análise crítica seguida de debate a respeito das responsabilidades de cada instituição direta e indiretamente envolvida em estudos clínicos, sendo importante identificá-las. Este estudo observou que $8,9 \%$ dos formulários não indicavam a instituição proponente do ensaio e que $84,7 \%$ dos pacientes participavam de estudos propostos por laboratórios farmacêuticos, $5,5 \%$ por universidades públicas e $0,9 \%$ por hospital privado.

Quanto aos países proponentes dos estudos realizados no centro, verificou-se que $1,5 \%$ dos formulários não apresentavam essa informação, $77,4 \%$ dos pacientes participavam de ensaios propostos por instituições norte-americanas, 9,5\% por instituições francesas, $6,7 \%$ por instituições brasileiras e $4,9 \%$ por instituições canadenses. Diante do exposto, é imprescidível que o discurso crítico sobre a terceirização de ensaios clínicos não enfatize apenas os perigos dessa prática, mas também aborde questões mais gerais de equidade e justiça que determinam o acesso a cuidados de saúde em países em desenvolvimento ${ }^{37}$.

\section{Considerações finais}

Mesmo com o aumento do número de pesquisas clínicas realizadas nas últimas décadas, pouco se debate sobre seus participantes. Apesar de este estudo ter sido desenvolvido em apenas um centro 
de pesquisa localizado no Nordeste do país e com número restrito de participantes, não podendo representar o cenário geral da pesquisa clínica no Brasil, é possível evidenciar as pessoas, identificando quem são e dando atenção às suas falas e interpretações. A intenção primária, nesse contexto, não é generalizar a situação revelada, mas contribuir com reflexões acerca do tema.

Existe relação direta entre maior participação em pesquisa clínica e estado de maior vulnerabilidade socioeconômica, e evidências indicam que as prioridades de investigação podem estar tendo precedência sobre as necessidades individuais do paciente. Os participantes da pesquisa tendem a não perceber os efeitos da investigação ou superestimar os benefícios médicos diretos de seu envolvimento nos estudos, mesmo sendo a busca pelo "tratamento médico" oferecido por meio do ensaio clínico o principal motivo de sua concordância em participar.
Destaca-se que a assinatura do TCLE não tem garantido na prática a expressão da autonomia. Documentos são assinados, mas informações essenciais para a decisão autônoma - como os objetivos da pesquisa, seus benefícios e riscos e o direito à continuidade do tratamento em caso de saída do estudo - são pouco conhecidas. Reitera-se: a ciência favorece tal prática questionável ao não analisar e discutir esses aspectos.

Conclui-se que o perfil dos participantes deste estudo e o conteúdo de seus discursos são sensíveis indicadores de vulnerabilidade e desigualdade social. Espera-se que esses resultados possam incitar o exercício e o diálogo interdisciplinar e crítico entre os diferentes atores e instituições envolvidos na área da pesquisa com seres humanos, visando impedir situações de desrespeito, desigualdade, vulnerabilidade e sofrimento moral.

\section{Referências}

1. Garrafa V, Lorenzo C. Helsinque 2008: redução de proteção e maximização de interesses privados. Rev Assoc Med Bras [Internet]. 2009 [acesso 12 dez 2019];55(5):514-8. DOI: 10.1590/ S0104-42302009000500010

2. Ravetz JR. Scientific knowledge and its social problems. 3a ed. Londres: Transations Publishers; 1973.

3. Lurie $P$, Wolfe SM. Unethical trials of interventions to reduce perinatal transmission of the human immunodeficiency virus in developing countries. N Eng J Med [Internet]. 1997 [acesso 12 dez 2019];337:853-6. DOI: 10.1056/NEJM199709183371212

4. Dainesi SM, Goldbaum M. Reasons behind the participation in biomedical research: a brief review. Rev Bras Epidemiol [Internet]. 2014 [acesso 12 dez 2019];17(4):842-51. DOI: 10.1590/1809-4503201400040004

5. Nappo SA, lafrate GB, Sanchez ZM. Motives for participating in a clinical research trial: a pilot study in Brazil. BMC Public Health [Internet]. 2013 [acesso 12 dez 2019];13:19. DOI: 10.1186/1471-2458-13-19

6. Zammar G, Meister H, Shah J, Phadtare A, Cofiel L, Pietrobon R. So different, yet so similar: metaanalysis and policy modeling of willingness to participate in clinical trials among Brazilians and Indians. PLoS One [Internet]. 2010 [acesso 12 jan 2019];5(12):e14368. DOI: 10.1371/journal.pone.0014368

7. Minayo MCS. O desafio do conhecimento: pesquisa qualitativa em saúde. $7 \underline{a}$ ed. São Paulo: Hucitec; 2000.

8. Bardin L. Análise de conteúdo. 4ạ ed. Lisboa: Edições 70; 2009.

9. Oduro AR, Aborigo RA, Amugsi D, Anto F, Anyorigiya T, Atuguba F et al. Understanding and retention of the informed consent process among parents in rural northern Ghana. BMC Med Ethics [Internet]. 2008 [acesso $12 \mathrm{dez} 2019$ ];9:12. DOI: 10.1186/1472-6939-9-12

10. Amorim KPC, Garrafa V, Melo AD, Costa AVB, Oliveira GCL, Lopes HG et al. Participantes de ensaios clínicos em oncologia: perfil e aspectos envolvidos nas suas decisões. Trab Educ Saúde [Internet]. 2018 [acesso 12 dez 2019];16(3):1381-402. DOI: 10.1590/1981-7746-sol00139

11. Shah JY, Phadtare A, Rajgor D, Vaghasia M, Pradhan S, Zelko H, Pietrobon R. What leads Indians to participate in clinical trials? A meta-analysis of qualitative studies. PLoS One [Internet]. 2010 [acesso $12 \mathrm{dez} 2019$ ];5(5):e10730. DOI: 10.1371/journal.pone.0010730

12. Stunkel L, Grady C. More than the money: a review of the literature examining healthy volunteer motivations. Contemp Clin Trials [Internet]. 2011 [acesso 12 dez 2019];32(3):342-52. DOI: 10.1016/j.cct.2010.12.003

13. Kass NE, Maman S, Atkinson J. Motivations, understanding, and voluntariness in international randomized trials. IRB [Internet]. 2005 [acesso 12 dez 2019];27(6):1-8. Disponível: https://bit.ly/36 KrOkr

14. Karim QA, Karim SSA, Coovadia HM, Susser M. Informed consent for HIV testing in a South African hospital: is it truly informed and truly voluntary? Am J Public Health [Internet]. 1998 [acesso 12 dez 2019];88(4):637-40. DOI: 10.2105/ajph.88.4.637 
15. Almeida CH, Marques RC, Reis DC, Melo JMC, Diemert D, Gazzinelli MF. A pesquisa científica na saúde: uma análise sobre a participação de populações vulneráveis. Texto Contexto Enferm [Internet]. 2010 [acesso $12 \mathrm{dez}$ 2019];19(1):104-11. DOI: 10.1590/S0104-07072010000100012

16. Kaewpoonsri N, Okanurak K, Kitayaporn D, Kaewkungwal J, Vijaykadga S, Thamaree S. Factors related to volunteer comprehension of informed consent for a clinical trial. Southeast Asian J Trop Med Public Health [Internet]. 2006 [acesso 12 dez 2019];37(5):996-1004. Disponível: https://bit.ly/3f5YkRE

17. Timmermans S, McKay T. Clinical trials as treatment option: bioethics and health care disparities in substance dependency. Soc Sci Med [Internet]. 2009 [acesso 12 dez 2019];69(12):1784-90. DOI: 10.1016/j.socscimed.2009.09.019

18. Gonorazky SE. Principio de precaución en investigación biomédica, seguridad, obligaciones post-investigación y eficacia terapéutica supuesta de las drogas experimentales: violaciones a la dignidad de los pacientes. Salud Colect [Internet]. 2011 [acesso 12 dez 2019];7(2):149-51. DOI: $10.18294 /$ sc.2011.370

19. Beauchamp TL, Childress JF. Principles of biomedical ethics. 7ạ ed. Nova York: Oxford University Press; 2013.

20. Meneguin S, Zoboli ELCP, Domingues RZL, Nobre MR, César LAM. Entendimento do termo de consentimento por pacientes partícipes em pesquisas com fármaco na cardiologia. Arq Bras Cardiol [Internet]. 2010 [acesso $12 \mathrm{dez}$ 2019];94(1):4-9. DOI: 10.1590/S0066-782X2010000100003

21. Ugalde A, Homedes N. Cuatro palabras sobre ensayos clínicos: ciencia/negocio, riesgo/beneficio. Salud Colect [Internet]. 2011 [acesso $12 \mathrm{dez}$ 2019];7(2):135-48. DOI: 10.18294/sc.2011.369

22. Rajaraman D, Jesuraj N, Geiter L, Bennett S, Grewal HMS, Vaz M, TB Trial Study Group. How participatory is parental consent in low literacy rural settings in low income countries? Lessons learned from a community based study of infants in South India. BMC Med Ethics [Internet]. 2011 [acesso 12 dez 2019];12:3. DOI: 10.1186/1472-6939-12-3

23. Instituto Brasileiro de Geografia e Estatística. Pesquisa nacional por amostra de domicílios: síntese de indicadores 2015 [Internet]. Rio de Janeiro: IBGE; 2015 [acesso 24 nov 2020]. Disponível: https://bit.ly/2Vkq7Vu

24. Passamai MPB, Sampaio HAC, Dias AMI, Cabral LA. Letramento funcional em saúde: reflexões e conceitos sobre seu impacto na interação entre usuários, profissionais e sistema de saúde. Interface Comun Saúde Educ [Internet]. 2012 [acesso 12 dez 2019];16(41):301-14. DOI: 10.1590/ S1414-32832012005000027

25. Garrafa V. Da bioética de princípios a uma bioética interventiva. Bioética [Internet]. 2005 [acesso 12 dez 2019];13(1):125-34. Disponível: https://bit.ly/32RdKo5

26. Zoboli E, Oselka G. Conflito de interesses na pesquisa clínica. Rev. Bioética [Internet]. 2007 [acesso 12 dez 2019];15(1):65-76. Disponível: https://bit.ly/32VxOWu

27. Goldacre B. Farmacêuticas da treta: como as empresas da indústria farmacêutica induzem os médicos em erro e fazem mal aos doentes. Lisboa: Bizâncio; 2013.

28. Sheppard VB, Cox LS, Kanamori MJ, Cañar J, Rodríguez Y, Goodman M et al. Brief report: if you build it, they will come. J Gen Intern Med [Internet]. 2005 [acesso 12 dez 2019];20:444-7. DOI: 10.1111/j.1525-1497.2005.0083.x

29. Mystakidou K, Panagiotou I, Katsaragakis S, Tsilika E, Parpa E. Ethical and practical challenges in implementing informed consent in HIV/aids clinical trials in developing or resource-limited countries. Sahara J [Internet]. 2009 [acesso 12 dez 2019];6(2):46-57. DOI: $10.1080 / 17290376.2009 .9724930$

30. Lobato-Victoria AC, Pichardo-García LMG. ¿En qué medida es verdad que los sujetos de investigación comprenden sus derechos? Pers Bioét [Internet]. 2013 [acesso 12 dez 2019];17(1):49-57. Disponível: https://bit.ly/36NndOx

31. Chaisson LH, Kass NE, Chengeta B, Mathebula U, Samandari T. Repeated assessments of informed consent comprehension among HIV-infected participants of a three-year clinical trial in Botswana. PLoS One [Internet]. 2011 [acesso 12 dez 2019];6(10):e22696. DOI: 10.1371/journal.pone.0022696

32. Joffe S, Cook EF, Cleary PD, Clark JW, Weeks JC. Quality of informed consent in cancer clinical trials: a cross-sectional survey. Lancet [Internet]. 2001 [acesso 12 dez 2019];358(9295):1772-7. DOI: 10.1016/S0140-6736(01)06805-2

33. Yuval R, Halon DA, Merdler A, Khader N, Karkabi B, Uziel K, Lewis BS. Patient comprehension and reaction to participating in a double-blind randomized clinical trial (Isis-4) in acute myocardial infarction. Arch Intern Med [Internet]. 2000 [acesso 12 dez 2019];160(8):1142-6. DOI: 10.1001/archinte.160.8.1142

34. Lacativa PGS, Szrajbman M, Silva DASM, Melazzi ACC, Gregório LH, Russo LAT. Perfil de sujeitos de pesquisa clínica em um centro ambulatorial independente. Ciênc Saúde Coletiva [Internet]. 2008 [acesso 12 dez 2019];13(3):1023-32. DOI: 10.1590/S1413-81232008000300025

35. Minnies D, Hawkridge T, Hanekom W, Ehrlich R, London L, Hussey G. Evaluation of the quality of informed consent in a vaccine field trial in a developing country setting. BMC Med Ethics [Internet]. 2008 [acesso 12 dez 2019];9:15. DOI: 10.1186/1472-6939-9-15 
36. Mandava A, Pace C, Campbell B, Emanuel E, Grady C. The quality of informed consent: mapping the landscape: a review of empirical data from developing and developed countries. J Med Ethics [Internet]. 2012 [acesso $12 \mathrm{dez}$ 2019];38(6):356-65. DOI: 10.1136/medethics-2011-100178

37. Kamat VR. Fast, cheap, and out of control? Speculations and ethical concerns in the conduct of outsourced clinical trials in India. Soc Sci Med [Internet]. 2014 [acesso 12 dez 2019];104:48-55. DOI: 10.1016/j.socscimed.2013.12.008

\section{Participação dos autores}

Karla Patrícia Cardoso Amorim participou de todas as etapas do estudo, concebendo-o com Volnei Garrafa. Alana Dantas de Melo, Andressa Vellasco Brito Costa, Gabriella Caldas Leonardo Oliveira, Heitor Giovanni Lopes, Eduardo Judene da Silva Pereira e Francisco Ademar Fernandes Júnior coletaram os dados. Todos os autores analisaram os dados, redigiram e revisaram o manuscrito.

\section{Correspondência}

Karla Patrícia Cardoso Amorim - Hospital Universitário Onofre Lopes. Departamento de Medicina Clínica. Av. Cordeiro de Farias, s/n, Petrópolis CEP 59012-300. Natal/RN, Brasil.

Karla Patrícia Cardoso Amorim - Doutora - amorimkarla@yahoo.com.br (iD) 0000-0003-4047-6073

Volnei Garrafa - Doutor - garrafavolnei@gmail.com

(iD) $0000-0002-4656-2485$

Alana Dantas de Melo - Graduada - alanadantas@gmail.com

(iD) 0000-0002-1524-613X

Andressa Vellasco Brito Costa - Graduada - andressavellasco04@gmail.com

(iD) 0000-0002-0851-7210

Gabriella Caldas Leonardo Oliveira - Graduada - gabi.leonardo.187@gmail.com

(iD) 0000-0001-5948-5696

Heitor Giovanni Lopes - Graduado - heitorgl@gmail.com

(iD) 0000-0002-0085-7413

Eduardo Judene da Silva Pereira - Graduado - eduardo.med.ufrn@gmail.com

(iD) 0000-0002-7300-653X

Francisco Ademar Fernandes Júnior - Graduado - ademar.ufrn@gmail.com

(iD) $0000-0001-5509-9763$ 